\title{
Serviço Social, mobilização e organização popular: uma sistematização do debate contemporâneo
}

\author{
Maria Lúcia Duriguetto \\ Universidade Federal de Juiz de Fora (UFJF)
}

\author{
Luiz Agostinho de Paula Baldi \\ Universidade Federal de Juiz de Fora (UFJF)
}

Serviço Social, mobilização e organização popular: uma sistematização do debate contemporâneo Resumo: O presente artigo versa sobre a intervenção do Serviço Social nos processos de mobilização e organização popular e, particularmente, sobre o debate contemporâneo que vem sendo realizado sobre o tema. Este debate é apresentado nas elaborações acadêmicas de autoras que tratam especialmente das funções pedagógica e educativa do assistente social e de sua inserção nas organizações da classe trabalhadora. Nesta sistematização, priorizam-se as formulações que vêm adquirindo relevância no debate profissional e que tecem algumas considerações necessárias para a análise e as prospectivas da relação da profissão com os processos de mobilização e organização popular.

Palavras-chave: Serviço Social. Debate profissional. Mobilização. Organização popular.

Social Work, Mobilization and Popular Organization: A Systematization of the Contemporary Debate Abstract: This article concerns the intervention of Social Work in processes of popular mobilization and organization and focuses in particular on the contemporary debate about the issue. This debate is presented in the academic production of authors specifically concerning the pedagogic and educational functions of social workers and their insertion in working class organizations. In this systematization, priority is given to formulations that have gained relevance in the professional debate and that offer some considerations needed for the analysis and to develop an outlook on the relationship of the profession with the processes of mobilization and popular organization.

Keywords: Social Work. Professional debate. Mobilization. Popular organization. 


\section{Introdução}

Este artigo constitui-se como parte dos estudos e das reflexões realizados para a pesquisa $A$ intervenção do Serviço Social nos processos de mobilização e organização popular ${ }^{1}$. O objetivo desta pesquisa é ampliar as análises acerca da apropriação da temática dos movimentos sociais pelo Serviço Social e das ações desenvolvidas pelo assistente social voltadas para a mobilização e a organização dos sujeitos que são alvo de sua ação; e também construir parâmetros e metodologias de intervenção profissional em "mobilização e organização popular".

Nossa expectativa é contribuir para a necessária revitalização do debate sobre a temática dos movimentos sociais, que tem sido pouco estudada na área do Serviço Social. De acordo com Iamamoto (2008, p. 461), "a área temática de menor investimento na pesquisa refere-se aos 'conflitos e movimentos sociais, processos organizativos e mobilização popular' , o que é motivo de preocupações". Soares (2010) também constata, aproximadamente, que entre os 495.116 trabalhos publicados nos anais dos CBAS e nos do Enpess, realizados entre 1995 e 2008, somente $3 \%$ dizem respeito à temática dos movimentos sociais. No interior deste conjunto, já exíguo, somente $6 \%$ das publicações expõem experiências de intervenção do assistente social junto aos movimentos. Este dado evidencia uma lacuna quanto, particularmente, à relação profissional entre o Serviço Social e os movimentos sociais.

O quadro sócio-histórico atual é de fortes ataques às classes subalternas, materializados nas regressividades dos contratos e das condições de trabalho impostos pela reestruturação produtiva ${ }^{2} \mathrm{e}$ nas contrarreformas na esfera estatal, que, no campo particular das políticas sociais, vêm assumindo contornos formulativos e operativos focalizadores e de um nítido caráter de assistencialização das políticas protetivas $^{3}$. Esses processos são acompanhados também pela regressividade das organizações e das lutas dos trabalhadores, seja no quadro sindical (marcado pela hegemonia de um sindicalismo colaborador nos processos de "gestão" da crise), seja no campo dos movimentos sociais (no qual se observa a acentuada presença de uma ideologia que orienta as ações na órbita do possibilitismo, que muitas vezes se traveste de governismo ${ }^{4}$ ).

Esse movimento da realidade impõe limites à efetivação do projeto ético-político hegemônico no Serviço Social brasileiro ${ }^{5}$. Esses limites advêm de determinantes estruturais e conjunturais - a dinâmica macroeconômica financista e as políticas a serem seguidas para alimentá-la; a "ausência de uma proposta alternativa à do capital na sociedade brasileira, capaz de unificar interesses sociais distintos relativos ao trabalho" e as políticas que incidem particu- larmente "nas bases materiais do projeto profissional", como as políticas sociais -, suas condições efetivas de formulação e operacionalização e as atuais condições em que se efetivam o processo de formação profissional e o exercício da profissão no Brasil (BRAZ, 2007, p. 7).

Entretanto, não concordamos, como sustentam Paulo Netto (2007) e Braz (2007), que essas condicionalidades estejam colocando em xeque o projeto ético-político. Sustentamos que, em face dessa realidade, nunca foi tão importante a necessidade de sua defesa. E, além dessa defesa, o necessário investimento reflexivo para o enfrentamento daquela lacuna identificada por Iamamoto (2008) e evidenciada por Soares (2010).

E nessa perspectiva que esse artigo é desenvolvido. Seu objetivo é contribuir para o debate acerca da relação da profissão com os processos de mobilização e de organização popular. Trazemos uma sistematização deste debate no Serviço Social brasileiro nas duas últimas décadas, período de implementação da agenda restritiva à efetivação do projeto ético-político. Projeto que, paradoxalmente (o que é mais um elemento que atesta a sua "não crise"), consolida-se nos vários âmbitos que o conformam (no campo da produção intelectual; no Código de Ética; na Lei de Regulamentação da profissão; nas Diretrizes Curriculares da Abepss; nos posicionamentos éticopolíticos do conjunto Cfess/Cress).

\section{A natureza contraditória da profissão e sua dimensão ideopolítica}

O Serviço Social é uma profissão essencialmente vinculada aos interesses classistas contraditórios que fundamentam a sociedade capitalista. Tem se afirmado como um tipo de especialização do trabalho coletivo, ao ser expressão de necessidades sociais derivadas da prática histórica das classes sociais no enfrentamento da "questão social" (IAMAMOTO; CARVALHO, 2006).

A "questão social" envolve os confrontos estabelecidos entre as classes fundamentais do capitalismo - proletariado e burguesia - e que se transmutam, na vida cotidiana, em diversas refrações que atingem os trabalhadores. Estes, que realizam trabalho e produzem a riqueza social, pelo mesmo processo são crescentemente explorados e apartados da riqueza por eles mesmos produzida. Ao identificarem seus interesses comuns, estes sujeitos ingressam no cenário sociopolítico, exercendo pressão junto ao empresariado e ao Estado por reconhecimento e atendimento de suas necessidades. Destarte:

A questão social não é senão as expressões do processo de formação e desenvolvimento da clas- 
se operária e de seu ingresso no cenário político da sociedade, exigindo seu reconhecimento como classe por parte do empresariado e do Estado (IAMAMOTO; CARVALHO, 2006, p. 77).

É quando a questão social assume um caráter necessariamente político que se imputa aos setores ocupantes do Estado a necessidade de enfrentá-la do mesmo modo. O Estado passará a intervir nas relações entre o empresariado e os trabalhadores, regulando o mercado de trabalho, por meio de leis trabalhistas, e ofertando serviços sociais - em cuja organização e implementação o assistente social será chamado a intervir - como forma de conter o processo de pauperismo e garantir os níveis mínimos de produtividade do trabalho.

A proposta destes serviços passa pela ótica das frações da classe dominante que ocupam o Estado ou as demais instituições privadas demandantes do assistente social, chegando a ele sempre de maneira determinada pela tradução que estes setores fazem da própria “questão social". Por essa razão, o enfrentamento será feito sempre no sentido de ocultar os conflitos de classe e conter as lutas dos trabalhadores.

Assim, a demanda imediata que se coloca ao assistente social é impressa pela classe oposta àquela que será alvo de sua intervenção: contratado por instituições ocupadas por setores da classe dominante, o assistente social intervém nas condições de vida dos trabalhadores, integrando-se ao processo de criação de condições indispensáveis ao funcionamento da força de trabalho, fonte de toda a riqueza social. É no movimento desta análise que se pode entender o Serviço Social como uma profissão de natureza contraditória, por ser necessariamente vinculada aos interesses colidentes de ambas as classes sociais que fundamentam a realidade social. Assim, a intervenção profissional do assistente social:

Responde tanto a demandas do capital como do trabalho e só pode fortalecer um ou outro pólo pela mediação de seu oposto. Participa tanto dos mecanismos de dominação e exploração como, ao mesmo tempo e pela mesma atividade, dá resposta às necessidades de sobrevivência da classe trabalhadora e da reprodução do antagonismo nesses interesses sociais, reforçando as contradições que constituem o móvel básico da história (IAMAMOTO; CARVALHO, 2006, p. 75).

De acordo com Iamamoto (2004), desconsiderar este movimento contraditório significa uma análise equivocada acerca da prática profissional, análise esta que pode resultar em dois comportamentos também equivocados: o fatalismo e o messianismo. O primeiro consiste na compreensão da ordem do capital como natural, sendo o Serviço Social uma profissão atrelada unicamente ao poder dominante, não restando, portanto, nada a fazer para além das tarefas formais e burocráticas atribuídas aos profissionais por seus demandantes. O segundo comportamento, messiânico, hipertrofia a potencialidade das intenções do sujeito profissional não considerando os processos sociais mais amplos e as determinações que a prática profissional incorpora. "O messianismo traduz-se numa visão 'heroica', ingênua, das possibilidades revolucionárias da prática profissional, a partir de uma visão mágica da transformação social" (IAMAMOTO; CARVALHO, 2006, p. 116).

Iamamoto (2008) destaca também a condição de trabalhador assalariado do assistente social, que o submete às condições de um contrato elaborado pelo empregador. É o empregador que delimita o rol de necessidades às quais o profissional deverá responder, bem como os recursos que lhe serão disponibilizados, interferindo, assim, nas condições em que se operam os atendimentos e nos efeitos da própria intervenção.

Não se trata de considerar unilateralmente as imposições do mercado de trabalho, o que conduziria o profissional apenas à sujeição às ações a ele imputadas. Segundo a autora (IAMAMOTO, 2008, p. 220), $\mathrm{o}$ assistente social possui uma relativa autonomia, que lhe permite imprimir à sua intervenção uma direção social. Tal autonomia é, igualmente, transpassada e dependente da correlação de forças presente na dinâmica da luta de classes e se expressa nos distintos espaços ocupacionais de forma particular. É no bojo das contradições de classe que atravessam e determinam a profissão, e a partir desta relativa autonomia, que se pode construir intervenções a serviço de um projeto de classe substanciado pelos interesses dos trabalhadores ${ }^{6}$.

É no e com o entendimento destes elementos, que determinam e particularizam a profissão, que refletimos acerca da inserção do Serviço Social nos processos de mobilização e organização popular, na perspectiva da possibilidade de um vínculo profissional com os movimentos e organizações dos trabalhadores $^{7}$. Isto significa analisar como o assistente social, enquanto trabalhador assalariado e considerando a própria natureza contraditória de sua intervenção profissional, pode atuar no sentido da promoção e do fortalecimento das organizações e lutas "coletivas" dos trabalhadores que são alvo de suas intervenções.

Compreendemos que, no limite circunscrito pela particular inserção do Serviço Social na divisão sociotécnica do trabalho, temos em sua "dimensão ideopolítica" a possibilidade de imprimir à ação profissional aquela intervenção acima destacada. Cabe aqui evidenciar a impreterível análise de Iamamoto (2006) de que o assistente social possui, na sua intervenção profissional, uma dimensão material- 
assistencial - que se configura através da prestação de serviços, dos benefícios, programas, projetos etc. - e também uma dimensão que é imaterial, e que influencia as formas de viver e de pensar dos sujeitos por ele atendidos. De acordo com a autora (IAMAMOTO, 2006, p. 68):

[...] o assistente social não trabalha só com coisas materiais. Tem também efeitos na sociedade como um profissional que incide no campo do conhecimento, dos valores, dos comportamentos, da cultura, que, por sua vez, têm efeitos reais interferindo na vida dos sujeitos.

Na dimensão imaterial, e que é “ideopolítica”, temos, de acordo com Paula (2009), a possibilidade de promover nos sujeitos que são alvo da intervenção profissional reflexões que lhes proporcionem mudanças nos valores, comportamentos e atitudes da população, das quais podem resultar processos de reivindicações, enfrentamentos e resistências coletivas das situações de sua vida cotidiana.

As possibilidades de a profissão contribuir prioritariamente para o acúmulo histórico de forças de uma das classes a qual se vincula inscrevem-se nos limites desta sociedade, uma vez que é uma profissão inserida na divisão sociotécnica do trabalho nos marcos desta ordem. Isto não significa a inexistência de possibilidades de uma intervenção profissional nos processos de mobilização popular na direção do fortalecimento dos interesses da classe trabalhadora. Entretanto, desconsiderar o tenso e contraditório terreno no qual o Serviço Social adquire existência nos conduz a fantasias sobre a profissão, ao messianismo, o que, definitivamente, não resulta em nenhuma contribuição profissional à formação de sujeitos coletivos.

É com e a partir dessa compreensão que apresentaremos, a seguir, uma sistematização de algumas reflexões presentes na produção intelectual do Serviço Social acerca da intervenção profissional em uma perspectiva formativa de sujeitos coletivos.

\section{O debate do Serviço Social nos processos de mobilização e organização popular}

Abordaremos aqui algumas contribuições sobre a possível relação interventiva do Serviço Social com os processos de mobilização e organização popular. Apesar das significativas reflexões que temos sobre este tema nos anos $1980^{8}$, nos marcos da renovação crítica do Serviço Social brasileiro, optamos aqui por abordar somente as análises mais recentes. Isto porque queremos refletir a partir do debate profissional que se construiu já num ambiente de maturação do projeto ético-político.
Ater-nos-emos às produções contidas na coletânea de textos Serviço Social: direitos sociais e competências profissionais (CFESS/ABEPSS, 2009), particularmente em dois textos atinentes à temática de nossa reflexão neste artigo. A escolha deste livro como referência se deu pela abrangente presença que o mesmo tem adquirido na categoria, entre profissionais e estudantes, contribuindo para a formação profissional e continuada, na direção do fortalecimento do projeto ético-político, versando sobre o trabalho profissional nos mais diversos âmbitos e aspectos. Retomamos também a obra de Abreu (2002), pelo significado adquirido pela mesma, de referência importante na temática de nosso interesse, referência esta que se expressa nos próprios textos contidos na coletânea de 2009.

Segundo Abreu (2002, p. 17), o Serviço Social possui uma função pedagógica que se materializa principalmente "por meio dos efeitos da ação profissional na maneira de pensar e agir dos sujeitos envolvidos nos processos da prática". Entre os perfis pedagógicos existentes na profissão, a autora defende a chamada "pedagogia emancipatória". Elucida que a pedagogia emancipatória surge no final da década de 1970 , no bojo da crise profissional que se configurou a partir da negação das bases conservadoras do Serviço Social, e se caracteriza pelo vínculo profissional à perspectiva histórica das classes subalternas e à sua luta pela construção de uma sociedade alternativa ao capitalismo.

Os elementos constitutivos desta pedagogia viriam das experiências das Comunidades Eclesiais de Base (CEBs) daquele momento, que, enraizadas nas práticas cotidianas das camadas populares, politizavam-nas e encorajavam-nas à auto-organização, realizando uma formação política através do debate crítico sobre as contradições sociais em meio a um processo de luta por melhorias de condições de vida e de contestação à ordem estabelecida. Para Abreu (2002, p. 133),

[...] as experiências das CEBs revelam-se espaços importantes de "politização das relações sociais e de intervenção dessas classes no movimento histórico na perspectiva de sua emancipação', processos estes entendidos aqui como principais vetores na constituição de uma pedagogia emancipatória.

A autora afirma que a base dessa "pedagogia" constitui-se de elementos como a solidariedade e a colaboração entre as classes subalternas, a mobilização, a capacitação e a organização das mesmas na medida em que condições históricas determinadas contribuem para subverter a ordem intelectual e moral do capital, na construção de uma nova cultura. A educação popular, em sua tendência de liberta- 
ção, vinculada principalmente a movimentos impulsionados pela Igreja Católica, tornar-se-á instrumento da prática do assistente social nos diferentes espaços de atuação profissional.

Na contemporaneidade, segundo a autora (2002, p. 206), a pedagogia emancipatória dos assistentes sociais comprometidos com as classes subalternas pode enveredar-se por duas tendências: uma restrita ao compromisso com as lutas das classes subalternas pela defesa dos direitos, no horizonte do Estado de bem-estar, e outra comprometida com essas lutas no sentido da superação da ordem burguesa e construção do socialismo. O horizonte encerrado nos direitos é atualmente predominante entre as próprias organizações das classes subalternas, que perderam o caráter revolucionário. Aponta, a partir disto, que os assistentes sociais, por serem ao mesmo tempo sujeitos e alvos das tendências assumidas por essas classes, possuem o desafio de identificar as possibilidades de avançar numa perspectiva emancipatória, "no sentido da construção de uma nova sociabilidade - a socialista".

Abreu (2002, p. 220) exemplifica a pedagogia emancipatória citando experiências, como, ouvidoria; orçamento participativo; renda mínima articulada à educação; balanços sociais; programas de qualidade de vida e de trabalho; fortalecimentos dos grupos subalternos direcionados à ampliação de direitos; denúncias da precariedade das condições de vida; e formas alternativas de produção e gestão das relações sociais. Indica também o Movimento dos SemTerra (MST), movimento social que conta com assistentes sociais em seu interior, como espaço fecundo à pedagogia emancipatória da prática profissional:

\footnotetext{
Alguns assistentes sociais inseridos nesse movimento aliam o trabalho profissional à sua condição de intelectual militante, respondendo a requisições que se situam no campo da organização e formação política dos grupos envolvidos, bem como no âmbito do atendimento de necessidades imediatas de subsistência desses grupos, articuladas a processos mais amplos direcionados à garantia com ampliação de direitos.
}

Nas contribuições de Abreu e Cardoso (2009, p. 594-595), as práticas de mobilização social e de organização são expressões das práticas educativas desenvolvidas pelas classes sociais na busca da ampliação de consensos em torno de seus projetos societários, na disputa pela hegemonia. O Serviço Social participa destes processos, recriando-os através do movimento da prática profissional. Portanto, as práticas de mobilização social e organização são realizadas, fundamentalmente, pelas classes sociais. Não são práticas exclusivas do assistente social, mas constitutivas da profissão e perpassam todo o corpo teórico-prático da mesma, corpo este tensionado pelos distintos projetos das classes.

O objetivo, segundo as autoras, é “desenvolver uma reflexão sobre os fundamentos das práticas educativas, particularizando as dimensões técnicooperativas e ético-políticas da mobilização social". Considerando que "a função pedagógica desempenhada pelo assistente social inscreve a prática profissional no campo das atividades educativas formadoras da "cultura",. A cultura entendida como atividades que incidem nos processos de formação de um "um modo de pensar, sentir e agir [...] no sentido gramsciano, como sociabilidade" (ABREU; CARDOSO, 2009, p. 594). Nesse contexto, afirmam que o "fundamento básico" da discussão sobre a função pedagógica desempenhada pelos assistentes sociais encontrase na premissa gramsciana de que "toda relação de hegemonia é eminentemente pedagógica" (GRAMSCI, apud ABREU; CARDOSO, 2009, p. 596).

As autoras defendem que as ações de mobilização e de organização são "elementos constitutivos e condição indispensável na concretização das práticas educativas desenvolvidas pelo assistente social". Essas ações vinculam-se a diferentes projetos societários das classes sociais: "uma direção circunscreve essas ações no horizonte histórico do Estado do bem-estar" e outra as vincula às lutas dos trabalhadores voltadas "para garantia e ampliação das conquistas sociais e políticas" e o "avanço dessas lutas na perspectiva do fortalecimento dos processos de superação da ordem burguesa e da conquista da emancipação humana". Para elas, a vinculação a uma ou outra direção "é determinada pelos compromissos profissionais estabelecidos com as classes sociais e se materializa pelos efeitos da ação profissional no modo de pensar e de agir dos sujeitos envolvidos nos processos das práticas educativas" (ABREU; CARDOSO, 2009, p. 600-601, 604-605). 
Sequenciam suas reflexões com indicações de práticas mobilizatórias na direção dos interesses das classes subalternas como o "fortalecimento dos espaços de luta dessas classes" que possibilitam a constituição de "sujeitos coletivos capazes de participar da construção da hegemonia das referidas classes; construção dos conselhos de direitos como "espaços de luta, espaços de enfrentamento entre interesses antagônicos, na explicitação de demandas das classes subalternas e implementação de respostas às suas necessidades"; o campo da comunicação social, que por meio da linguagem escrita e audiovisual pode impulsionar a consciência crítica e a formação de sujeitos coletivos; produção de dados relativos às diferentes expressões da questão social vividas nos diferentes espaços sócio-ocupacionais (CARDOSO, 1995 apud ABREU; CARDOSO, 2009, p. 603).

Na elaboração de Cardoso e Lopes (2009, p. 49), encontramos duas referências institucionais distintas para a relação do assistente social com os movimentos e organizações da classe trabalhadora: as próprias organizações dos trabalhadores como empregadoras desses profissionais; e a possibilidade de se trabalhar junto às mesmas a partir e por meio de outras inserções institucionais. Um pressuposto analítico é que o trabalho profissional desenvolvido tanto nos espaços organizativos dos trabalhadores quanto em outros espaços sócio-ocupacionais "pode assumir a direção político-ideológica de emancipação humana dessa classe, bem como a de sua subalternização pelos setores dominantes".

As autoras remontam de forma genérica à categoria de "hegemonia" de Gramsci ${ }^{10}$, elucidando que a "organização e a consciência de classe são condições indispensáveis para essa conquista política pelas classes subalternas". E é nestes processos de organização e de formação de consciência de classe que, para elas, encontram-se possibilidades de atuação do assistente social junto às organizações da classe trabalhadora, entre as quais destacam:

1) a participação no desenvolvimento de propostas de formação político-organizativa, que possibilite a essas classes a apreensão crítica das contradições econômicas e político-ideológicas inerentes às sociedades capitalistas; a criação de formas próprias de reprodução e de resistência no enfrentamento cotidiano com os interesses das classes adversárias e a construção de formas de superação da opressão por estas classes; 2) desenvolvimento de propostas eminentemente educativas de fortalecimento das organizações da classe trabalhadora e de processos de constituição ideológica das classes subalternas na luta pela construção de uma alternativa emancipatória da classe trabalhadora e de toda humanidade (CARDOSO; LOPES, 2009, p. 471).
As autoras também tomam o MST como exemplo de um movimento social combativo e que conta com assistentes sociais no seu interior. Ressaltam que muitos assistentes sociais não se reconhecem como tais no movimento, atuando somente como militantes, mas que o trabalho que desenvolvem é expressão concreta da profissão, a partir das demandas do movimento à equipe interprofissional. Estas demandas situam-se, basicamente, nos eixos da educação e da produção. No primeiro, trata-se de demandas voltadas à educação formal e à formação política dos assentados, na direção da construção da consciência de classe; e no segundo, as demandas envolvem o fortalecimento das cooperativas agrícolas, por meio das quais se dá o processo de produção.

Os assistentes sociais inseridos nas equipes interprofissionais atuam principalmente no incentivo e apoio político-organizativo às formas coletivas de trabalho, como mutirões, associações e grupos coletivos; na mobilização e organização das famílias trabalhadoras para inserirem-se nos processos de educação formal e política, tidas como fundamentais para o avanço da consciência de classe; e na produção e socialização de conhecimentos que contribuam para o fortalecimento de sujeitos coletivos (ABREU; CARDOSO, 2009, p. 473).

Por fim, as autoras (2009, p. 474-475) indicam algumas estratégias que consideram passíveis e importantes de serem realizadas pelos assistentes sociais junto nos espaços de organização da classe trabalhadora: prestar assessoria técnica e apoio político aos setores organizados da classe trabalhadora, na criação de mecanismos de resistência e de luta; desenvolver junto aos trabalhadores atividades educativas formadoras de um modo de pensar e agir que lhes permitam a constituição de um núcleo organizatório que leve adiante um projeto coletivo de transformação social; e desenvolver um trabalho pedagógico que contribua para os trabalhadores formularem e implementarem uma política que concretize a participação das massas, construindo novas relações hegemônicas.

\section{Algumas considerações finais}

No Serviço Social, como visto, é na dimensão ideopolítica da intervenção que reside a possibilidade dos assistentes sociais influenciarem criticamente os valores, comportamentos e ações dos sujeitos com os quais trabalham. Contudo, a análise do constructo teórico que temos acumulado sobre esta relação do Serviço Social com os processos de mobilização e organização popular, apesar das significativas contribuições, ainda nos revela problemáticas e desafios em aberto.

Sobre a chamada pedagogia emancipatória, defendida por Abreu (2002), concordamos com a aná- 
lise realizada por Iamamoto (2008, p. 323) de que tal perspectiva "[...] torna fluidos os limites entre profissão e militância política revolucionária, pois equaliza inserções e dimensões diferenciadas vividas pelo assistente social, enquanto profissional assalariado e enquanto cidadão político."

De acordo com Iamamoto (2008, p. 326), o que Abreu (2002) estaria propondo é "um possível 'Serviço Social socialista', em uma profissão exercida predominantemente na esfera do Estado burguês, nas corporações empresariais e nas chamadas 'organizações da sociedade civil"',

No texto de Abreu e Cardoso (2009, p. 594), como apresentado na exposição de suas reflexões, está expresso que o objetivo é “desenvolver uma reflexão sobre os fundamentos das práticas educativas, particularizando as dimensões técnico-operativas e éticopolíticas da mobilização social [...]".

Particularmente, em relação à dimensão técnicooperativa da função educativa ou pedagógica de mobilização e organização popular, continua existindo uma lacuna que necessita ser debatida e aprofundada. Nos textos apresentados encontramos indicações gerais de práticas mobilizatórias na direção dos interesses das classes subalternas. No entanto, dada a pouca densidade destas indicações, constatamos a necessidade de avanços na formulação de indicativos teórico-operativos do trabalho profissional do Serviço Social nos processos de mobilização e organização popular.

Também nos chama a atenção, nos textos analisados, a recorrência a algumas categorias gramscianas, por exemplo, hegemonia, cultura e intelectual orgânico, como constitutivas dos fundamentos das práticas educativas. Data da década de 1980, a recorrente interlocução do Serviço Social brasileiro com o pensamento do marxista italiano. As análises de Gramsci acerca do Estado, da sociedade civil, da cultura e de hegemonia contribuíram significativamente para o processo de renovação do Serviço Social brasileiro ${ }^{11}$.

Ciente de que os conteúdos dessas categorias em Gramsci estão organicamente relacionados à construção de um novo projeto societário, que se contraponha ao do capital (função que ele atribui de maneira forte ao partido político), consideramos imperioso reconhecer, como ressalta Simionatto (2011, p. 25) "o significativo arco de mediações que oferece para pensar as ciências sociais particulares e os projetos profissionais, de forma a contribuírem para a efetivação da práxis social". Nessa direção, entendemos a necessidade de explicar e compreender como, na particularidade prático-social da profissão, pode se traduzir o conteúdo ético-político do qual se revestem essas categorias em Gramsci. Mais exatamente: o problema consiste em determinar as mediações que conectam a profissão a essas categorias.
Outro aspecto a ser problematizado é a vinculação que Abreu e Cardoso estabelecem entre as ações de mobilização e de organização aos diferentes projetos societários das classes sociais. Nesta assertiva, a particularidade dos projetos profissionais necessita ser melhor explicitada em relação aos projetos sociais ou societários, como elucida Paulo Netto (1999), bem como os elementos que configuram a natureza da profissão, conforme visto anteriormente. Ancorados nessas reflexões, podemos vislumbrar elementos elucidativos da relação das ações de mobilização e organização empreendidas pelos assistentes sociais com os processos de emancipação política e de emancipação humana ${ }^{12}$.

Na elaboração de Cardoso e Lopes (2009), temos a reflexão sobre o trabalho do assistente social nas organizações da classe trabalhadora, em destaque a experiência do MST. Entretanto, não estabelecem uma distinção clara entre os militantes que são assistentes sociais, mas não se inserem no movimento como tais, e os assistentes sociais que são demandados para intervirem profissionalmente no movimento. Quando esta diferenciação não é devidamente realizada, a análise tende também a tornar fluidos os limites entre a profissão e a militância política, como aponta Iamamoto (2008) sobre a reflexão de Abreu (2002).

As autoras também apontam, tal como Abreu e Cardoso (2009), a possibilidade de o assistente social atuar em processos de formação política de militantes dos movimentos sociais. De acordo com Iamamoto (2004, p. 47), verifica-se uma ausência da atuação profissional "em organizações e associações próprias da classe trabalhadora, por elas criadas e geridas, assim como a falta de vínculos sólidos com seus movimentos sociais autônomos". Consideramos que, dada a particularidade do Serviço Social como profissão inserida na divisão sociotécnica do trabalho, devemos investigar se os movimentos sociais têm demandado a intervenção profissional dos assistentes sociais. E, se a resposta for sim, qual tem sido o conteúdo destas experiências, para compreender quais as competências que o assistente social pode vir a assumir nestes espaços.

No debate da relação da profissão com os movimentos sociais também aparecem, com certa frequência, indicativos de intervenção que apontam para a educação popular. Ressaltamos que é preciso amadurecer melhor, no debate profissional, a compreensão do conteúdo teórico que perpassa as reflexões situadas sob esta denominação. O próprio conceito de educação popular apresenta-se hoje em relativa polissemia. Embora remeta, de modo geral, à mobilização, conscientização e organização das classes subalternas, seus agentes pautam-se em referências teóricas e políticas diversas, o que resulta em projetos que não necessariamente convergem para o mesmo horizonte sociopolítico ${ }^{13}$. 
Entre os diversos autores que sistematizaram reflexões sobre a educação popular ${ }^{14}$, vemos uma pluralidade de termos (como educação política, classes populares, pedagogia do oprimido, classes subalternas, classe trabalhadora, povo, revolução, justiça social etc.) que nos permite apontar para a relativa polissemia da qual falamos anteriormente. Também na perspectiva interventiva das próprias organizações que atualmente desenvolvem a educação popular, vemos diferenciações, como, por exemplo, o Núcleo de Educação Popular 13 de Maio (NEP) cujo trabalho enfatiza a técnica (especialmente dinâmicas de grupo baseadas no psicodrama) em relação ao Centro de Educação Popular (Cepis), que focaliza os princípios e valores dos militantes, numa perspectiva que considera a educação popular como todo o conjunto das ações que constituem a militância.

O que, por fim, queremos destacar é que, ainda que esteja muitas vezes presente nas elaborações do Serviço Social e sendo reclamado para a incorporação na intervenção profissional, o conceito de educação popular dota de uma complexidade que exige esforços intelectuais específicos com a finalidade de desvendá-lo.

\section{Referências}

ABREU, M. M. Serviço Social e a organização da cultura: perfis pedagógicos da prática profissional. São Paulo: Cortez, 2002 .

ABREU, M. M.; CARDOSO, F. G. Mobilização social e práticas educativas. In: ABEPSS; CFESS (Org.). Serviço Social: direitos sociais e competências profissionais. Brasília: Cfess/Abepss, UnB, 2009, p. 593-608.

ANTUNES, R. Os sentidos do trabalho: ensaios sobre a afirmação e negação do trabalho. São Paulo: Boitempo, 1999.

BALDI, L. A. de P. Serviço Social e educação popular. Trabalho de Conclusão de Curso (Graduação em Serviço Social) - UFJF, Juiz de Fora, 2010.

BRASIL. Presidência da República. Lei n. 8.662, de 7 de junho de 1993. Dispõe sobre a profissão de assistente social e dá outras providências. Disponível em: <http://www.planalto.gov.br/ ccivil 03/leis/L8662.htm>. Acesso em: 20 jan. 2012.

BRAZ, M. A hegemonia em xeque. Projeto ético-político do Serviço Social e seus elementos constitutivos. Revista Inscrita, Cfess: Brasília, n. 10, p. 4-10, 2007.

BRAZ, M.; TEIXEIRA, J. B. O projeto ético-político do Serviço Social. In: ABEPSS; CFESS (Org.). Serviço Social: direitos sociais e competências profissionais. Brasília: Cfess/Abepss, UnB, 2009, p. $185-201$
CARDOSO, F. G.; LOPES, J. B. O trabalho do assistente social nas organizações da classe trabalhadora. In: ABEPSS; CFESS. (Org.). Serviço Social: direitos sociais e competências profissionais. Brasília: Cfess/Abepss, UnB, 2009, p. 461477.

CFESS. Resolução n. 273/93 de 13 março de 1993. Código de Ética profissional dos assistentes sociais. Disponível em: <http:/ /www.cfess.org.br/arquivos/CEP 1993.pdf>. Acesso em: 12 jan. 2012.

CFESS/ABEPSS. Serviço Social: direitos sociais e competências profissionais. Brasília: Cfess/Abepss, UnB, 2009.

DURIGUETTO, M. L. Ofensiva capitalista, despolitização e politização dos conflitos de classe. Temporalis, Abepss, n. 16, p. 45-66, 2009

FILGUEIRAS, L.; GONÇALVES, R. A economia política do governo Lula. Rio de Janeiro: Contraponto, 2007.

IAMAMOTO, M. V. 20 anos do livro Relações Sociais e Serviço Social no Brasil: uma leitura retrospectiva. Temporalis, Abepss, Suplemento, ano III, 2002.

Renovação e conservadorismo no Serviço Social: ensaios críticos. São Paulo: Cortez, 2004.

O Serviço Social na contemporaneidade: trabalho e formação profissional. São Paulo: Cortez, 2006.

Serviço Social em tempo de capital fetiche: capital financeiro, trabalho e questão social. São Paulo: Cortez, 2008.

IAMAMOTO, M. V.; CARVALHO, R. de. Relações sociais e Serviço Social no Brasil: esboço de uma interpretação históricometodológica. São Paulo: Cortez, 2006.

MONTAÑO, C.; DURIGUETTO, M. L. Estado, classe e movimento social. São Paulo: Cortez, 2010.

MOTA, A. E. da. Questão social e Serviço Social: um debate necessário. In:__. (Org.). O mito da assistência social. São Paulo: Cortez, 2008, p. 21-57.

PALUDO, C. Educação popular em busca de alternativas. Uma leitura desde o campo democrático popular. Porto Alegre: Tomo Editorial; Camp, 2001.

PAULA, L. P. G. de. Dimensão ídeopolítica da intervenção profissional do assistente social: o debate teórico sobre sua conformação. Dissertação (Mestrado em Serviço Social) Universidade Federal de Juiz de Fora, Juiz de Fora, 2009.

PAULO NETTO, J. A Construção do projeto ético-político do Serviço Social frente à crise contemporânea. In: CFESS-ABEPSS. Capacitação em Serviço Social e política social: crise 
contemporânea, questão social e Serviço Social, módulo 1. Brasília: CEAD, 1999.

. Das ameaças à crise. Revista Inscrita, Cfess: Brasília, $\mathrm{n}$. 10, p. 37-40, 2007.

SILVA e SILVA, M. O. da. O Serviço Social e o popular: resgate teórico-metodológico do projeto profissional de ruptura. São Paulo: Cortez, 2002.

SIMIONATTO, I. Marxismo gramsciano e Serviço Social: interlocuções mais que necessárias. Em Pauta, Revista da Faculdade de Serviço Social da UERJ, n. 27, p. 17-34, jul. 2011.

SOARES, M. G. M. A relação do Serviço Social com os movimentos sociais na contemporaneidade. In: ENCONTRO NACIONAL DE PESQUISADORES EM SERVIÇO SOCIAL, XII, 2010. Anais... Rio de Janeiro: Abepss. CD-Rom.

TUMOLO, P. S. Da contestação à conformação: a formação sindical da CUT e a reestruturação produtiva. Campinas: Unicamp, 2002.

\section{Notas}

1 Pesquisa em desenvolvimento na Faculdade de Serviço Social da Universidade Federal de Juiz de Fora, sob Coordenação da Profa. Dra. Maria Lúcia Duriguetto e financiada pelo CNPq.

2 Conforme Antunes (1999) e Tumolo (2002).

3 Conforme Filgueiras e Gonçalves (2007) e Mota (2008).

4 Outras regressividades nos processos de organização dos movimentos sociais podem ser também encontradas em Duriguetto (2009).

5 Para uma didática exposição dos elementos constitutivos do projeto ético-político profissional consultar Braz e Teixeira (2009). Elementos que conformam as particularidades de um projeto profissional em relação a projetos societários estão em Paulo Netto (1999).

6 "A possibilidade de imprimir uma direção social aoexercício-como refrações no seu conteúdo e no modo de operá-lo-decorre da relativa autonomia que dispõe o assistente social, respaldada juridicamente naregulamentaçãoda profissão,naformaçãouniversitáriaespecializada enocódigo deética. Essa autonomiaétensionada pelas exigências dos empregadores-quanto aos propósitos, às demandas, regulamentações específicas incidentes sobre o exercício assim como referentes à organização do trabalho, às funções e atribuições, à política de gestão da força de trabalho ès determinações contratuais - salário, jornada etc" (IAMAMOTO, 2002, p. 115).

7 Ressaltamos que esta relação perpassa os princípios e as diretrizes que orientam as formulações do projeto ético-político, sendo inclusive explicitada e garantida na lei de regulamentação da profissão, que determina como competência do assistente social "prestar assessoria e apoio aos movimentos sociais em matéria relacionada às políticas sociais, no exercício e na defesa dos direitos civis, políticos e sociais da coletividade" (BRASIL, 1993, art. 4, parágrafo IX) e no Código de Ética do assistente social, que afirma como direito do profissional "apoiar e/ou participar dos movimentos sociais e organizações populares vinculados à luta pela consolidação e ampliação da democracia e dos direitos de cidadania" e assevera como um dever do profissional "respeitar a autonomia dos movimentos popularese das organizações das classes trabalhadoras" (CFESS, 1993, art. 12, alínea b; art.13, alínea c).

8 Uma sistematização do debate deste período encontra-se em Silva e Silva (2002).

9 Revisitando a história da profissão, a autora identifica, além da pedagogia emancipatória, outros dois perfis pedagógicos da prática do assistente social. O primeiro é a pedagogia da "ajuda”, fundada numa visão psicologista da questão social, reduzida às suas manifestações individuais. Esse perfil pedagógico era pautado na "assistência social individualizada de cunho moralizador direcionada para a 'reforma moral e a reintegração social'" (ABREU, 2002, p. 85 , grifos da autora). O segundo é a pedagogia da "participação", que se desenvolve no Serviço Social com as propostas de "desenvolvimento de comunidade", no contexto do projeto desenvolvimentista modernizador. Essas propostas eram pautadas no entendimento de que os problemas sociais são passíveis de tratamento no âmbito de cada comunidade e a participação popular destas comunidades nos programas de governos era tida como fundamental para a integração social e a modernização do país.

10 Explicitam também que para Gramsci é decisivo o papel dos intelectuais e do partido na construção de uma nova hegemonia, mas não desenvolvem o conteúdo dessas categorias, bem como a relação delas com o trabalho do assistente social (CARDOSO; LOPES, 2009, p. 471).

11 Como elucida Simionatto (2011,p. 18), a partir da década de 1980, as categorias gramscianas estão presentes na produção intelectual da profissão seja para o desenvolvimento de análises relativas aos processos sociais seja para análises da especificidade do fazer profissional; nos currículos dos cursos de graduação e de pósgraduação e nas produções das dissertações e teses.

12 Para uma didática apresentação acerca dos processos e das particularidades que conformam a emancipação política e a emancipação humana, consultar Montaño e Duriguetto (2010).

13 Para conhecer melhor essa diversidade, indicamos Paludo (2001, cap. IV).

14 Tais como Silvia M. Manfredi, Carlos Rodrigues Brandão, Paulo Freire, Mauro Luis Iasi, Andréa Pires Rocha e Ranulfo Peloso (2009), cujo debate encontra-se sistematizado em Baldi (2010). 


\section{Maria Lúcia Duriguetto}

maluduriguetto@gmail.com

Doutora em Serviço Social pela Universidade Federal do Rio de Janeiro (UFRJ)

Professora adjunta da Faculdade de Serviço Social da Universidade Federal de Juiz de Fora (UFJF)

\section{Luiz Agostinho de Paula Baldi}

luiz.baldi@yahoo.com.br

Assistente Social

Mestrando do Programa de Pós-Graduação em Ser-

viço Social da UFJF

\section{UFJF - Faculdade de Serviço Social}

Campus Universitário

Bairro Martelos

Juiz de Fora - Minas Gerais

CEP: 36036-330 